\title{
Safety of bilateral same-day intravitreal injections of anti-vascular endothelial growth factor agents
}

\author{
This article was published in the following Dove Press journal: \\ Clinical Ophthalmology \\ I February 2017 \\ Number of times this article has been viewed
}

\author{
Miguel Ruão' \\ María Andreu-Fenoll ${ }^{2}$ \\ Rosa Dolz-Marco 2 \\ Roberto Gallego-Pinazo² \\ 'Department of Ophthalmology, \\ Centro Hospitalar Entre Douro e \\ Vouga, Santa Maria da Feira, Portugal; \\ ${ }^{2}$ Unit of Macula, Department \\ of Ophthalmology, University \\ and Polytechnic Hospital La Fe, \\ Valencia, Spain
}

Purpose: The aim was to evaluate the safety of bilateral same-day injections with intravitreal antiangiogenic drugs for macular diseases.

Methods: Cross-sectional retrospective review of unilateral and bilateral same-day antiangiogenic injections was conducted between January 2011 and March 2016 in the Unit of Macula, University and Polytechnic Hospital La Fe (Valencia, Spain). A total of 8,172 injections were administered, among which 6,560 were unilateral and 1,612 were bilateral injections. Patients were included in the study regardless of the diagnosis. Ranibizumab and aflibercept were the antiangiogenic drugs used. The presence of endophthalmitis or retinal detachment was evaluated. Results: A total of $1(0.012 \%)$ culture-proven endophthalmitis and $19(0.233 \%)$ acute intraocular inflammations were registered. In the unilateral injections group, there were $18(0.274 \%)$ acute intraocular inflammations and $1(0.015 \%)$ culture-proven endophthalmitis. One $(0.062 \%)$ of the 1,612 bilateral same-day injections had a unilateral acute intraocular inflammation, and there were no culture-proven endophthalmitis in this group.

Conclusion: Bilateral same-day injections are more convenient for patients and their caregivers than the unilateral injections administered on different days. In our study, the prevalence of culture-proven endophthalmitis and acute intraocular inflammation was lower in the bilateral injections than in the unilateral group. These data support the idea that bilateral same-day injections are a safe and valid treatment to use in our clinical practice.

Keywords: bilateral, intravitreal, injections, anti-VEGF, endophthalmitis

\section{Introduction}

Intravitreal injections of anti-vascular endothelial growth factor (anti-VEGF) are extensively used in the treatment of several ophthalmic diseases, including neovascular age-related macular degeneration, diabetic macular edema, macular edema secondary to retinal venous occlusive diseases, and other causes of choroidal neovascularization such as myopia. ${ }^{1-3}$

Patients often require bilateral treatment. Several physicians administer the first injection in one eye, followed by the second injection in the fellow eye a week later. In these ophthalmic diseases, monthly examinations are frequent, and this second injection increases the patients' and caregivers' burden, and the physicians' as well. ${ }^{4}$ In order to avoid this burden, bilateral same-day injections are a very common practice in many countries. In a survey made in the United States, $46 \%$ of the retina specialists use bilateral injections. ${ }^{5}$

Bilateral same-day injections are usually well tolerated, but patients should be properly advised of the risks, as well as of the symptoms of endophthalmitis., ${ }^{4,-10}$

The rate of infectious endophthalmitis after anti-VEGF intravitreal injections has been described to be between 1 in $1,291(0.078 \%)$ and 1 in 4,500 $(0.022 \%) .{ }^{11,12}$ 
McCannel et $\mathrm{al}^{13}$ in a meta-analysis reported a rate of $0.049 \%$ of endophthalmitis after intravitreal anti-VEGF.

In a bilateral same-day injection study, the incidence of culture-proven endophthalmitis was $0.065 \%$, and the incidence of acute intraocular inflammation was $0.033 \%{ }^{1}$

Acute myocardial infarction, strokes, and thromboembolic events are systemic adverse side effects reported with the intravitreal injections of anti-VEGF, ${ }^{2,14}$ but it is still unknown if bilateral same-day injections have an increased risk of systemic side effects. ${ }^{6}$

The MARINA ${ }^{2}$ trial showed that patients who received unilateral intravitreal injections of ranibizumab $0.3 \mathrm{mg}$ and $0.5 \mathrm{mg}$ had myocardial infarction rates of $2.5 \%$ and $1.3 \%$ respectively, and the sham treatment group of $1.7 \%$. The rate of stroke was $1.3 \%$ with $0.3 \mathrm{mg}, 2.5 \%$ with $0.5 \mathrm{mg}$, and $0.8 \%$ in the sham group. None of these were statistically significant.

Several recommendations have been made for perioperative care in intravitreal injections. Topical antibiotics pre- or postinjection have not been shown to be effective in the prevention of endophthalmitis, and these could select more virulent microorganism. This way, preinjection antisepsis becomes even more significant and should be applied both before and after topical or subconjunctival anaesthesia. Recommendations on the use of face masks, or maintaining silence, have been made too. ${ }^{15}$

The purpose of this study was to evaluate the safety of unilateral and bilateral same-day injections, administered in the same hospital by the same two surgeons (RGP and RDM).

\section{Methods}

Cross-sectional retrospective review of medical records of unilateral and bilateral same-day anti-VEGF injections was conducted in the Macula Unit of the University and Polytechnic Hospital La Fe (Valencia) between January 2011 and March 2016. A total of 8,172 injections were administered in 1,024 patients. Only ranibizumab and aflibercept were used. Patients were included regardless the diagnosis. Agerelated macular degeneration, diabetic retinopathy, retinal vein occlusion, and myopic choroidal neovascularization were the major indications for injections. All injections were administered by two ophthalmologists (RGP and RDM). None of the exclusion criteria were used. The number of postinjection endophthalmitis was evaluated.

This study was approved by Instituto de Investigaciones Sanitarias La Fe. Informed consent was included in the study protocol and signed by each patient.

\section{Intravitreal anti-VEGF injection method}

The Unit of Macula of the Department of Ophthalmology of the University Hospital La Fe (Valencia, Spain) administers intravitreal injections in a controlled ambient surgery cabin, the Arc Steril (Carl Zeiss Meditec, Inc., Jena, Germany). This unit creates ambient with an extremely low level of particles and microorganisms suspended in the air in a standard consultation room, due to the sterile laminar flow system present in the equipment. ${ }^{16}$

The preparation of the products was made in a laminar flow chamber in the hospital pharmacy. Individual doses were then transported to the Macula Unit.

The ophthalmologist administered the injection without surgical scrubs or face mask, but we washed our hands before each procedure. Patients used their own clothes, without hospital gown or face masks. Before the procedure, topical anesthetic and diluted povidone-iodine were instilled in the conjunctiva and cornea. No speculum was used. The intravitreal injection was made in the sclera $3-3.5 \mathrm{~mm}$ from the limbus with a 30 -gauge needle containing $0.05 \mathrm{~mL}$ of anti-VEGF. Care was taken to maintain silence during the injection. Then, a new sterilize set of needle and syringe were used for the fellow eye. Diluted povidone-iodine was again instilled in the conjunctiva, as well as ofloxacin ointment.

All data were analyzed between March and April of 2016 and collected in an Microsoft ${ }^{\circledR}$ Excel $^{\circledR}$ (Microsoft Corporation, Redmond, WA, USA) document.

\section{Results}

A total of 1,024 patients were administered with 8,172 injections. Six thousand five hundred and sixty unilateral injections were administered, 5,805 with ranibizumab and 755 with aflibercept. One thousand six hundred and twelve bilateral injections were made, 1,495 with ranibizumab and 117 with aflibercept. Table 1 exposes the distribution of injections per year.

The most common injection cause was age-related macular degeneration, responsible for 4,557 injections, followed

Table I Number of unilateral/bilateral injections per year and anti-VEGF used

\begin{tabular}{clllll}
\hline Year & Ranibizumab & Aflibercept & Unilateral & Bilateral & Total \\
\hline 2011 & 738 & 0 & 586 & 152 & 738 \\
2012 & 571 & 0 & 497 & 74 & 571 \\
2013 & 1,652 & 197 & 1,367 & 482 & 1,849 \\
2014 & 2,125 & 280 & 1,927 & 478 & 2,405 \\
2015 & 1,777 & 346 & 1,753 & 370 & 2,123 \\
2016 & 437 & 49 & 430 & 56 & 486 \\
Total & 7,300 & 872 & 6,560 & 1,612 & 8,172 \\
\hline
\end{tabular}

Abbreviation: anti-VEGF, anti-vascular endothelial growth factor. 
Table 2 Indications for injections

\begin{tabular}{llllll}
\hline Year & $\begin{array}{l}\text { Age-related macular } \\
\text { degeneration }\end{array}$ & $\begin{array}{l}\text { Diabetic } \\
\text { retinopathy }\end{array}$ & $\begin{array}{l}\text { Retinal vein } \\
\text { occlusion }\end{array}$ & $\begin{array}{l}\text { Myopic choroidal } \\
\text { neovascularization }\end{array}$ \\
\hline 2011 & 341 & 159 & 48 & 66 & \multicolumn{1}{c}{ Other } \\
2012 & 321 & 103 & 70 & 37 & 424 \\
2013 & 1,036 & 441 & 186 & 84 & 102 \\
2014 & 1,339 & 559 & 303 & 128 & 76 \\
2015 & 1,228 & 380 & 265 & 164 & 86 \\
2016 & 292 & 83 & 50 & 41 & 20 \\
Total & 4,557 & 1,725 & 922 & 520 & 448 \\
\hline
\end{tabular}

by diabetic retinopathy, retinal vein occlusion, and myopic choroidal neovascularization. The different causes for intravitreal injections are shown in Table 2.

In the 8,172 injections, one culture-proven endophthalmitis and 19 acute intraocular inflammations were diagnosed. This gives us a global endophthalmitis' prevalence of $0.012 \%$ and acute intraocular inflammation of $0.233 \%$. Only one $(0.062 \%)$ of the 1,612 bilateral same-day injections had a unilateral acute intraocular inflammation, and there were no culture-proven endophthalmitis in this group. In the unilateral injections group, there were $18(0.274 \%)$ acute intraocular inflammations and $1(0.015 \%)$ culture-proven endophthalmitis. Ranibizumab had a lower rate of acute intraocular inflammation, when compared with aflibercept, but the only case of culture-proven endophthalmitis was in a Ranibizumab patient. Table 3 shows the distribution of endophthalmitis per year and anti-VEGF used.

The only patient with a culture-proven endophthalmitis was an 83-year-old male, without imunosupression or other relevant comorbidity, and was injected with ranibizumab for a neovascular age-related macular degeneration. Culture was positive to Streptococcus pneumoniae. Intravitreal antibiotics and pars plana vitrectomy were performed, and the final visual acuity was 20/500.

Five cases $(0.076 \%)$ of retinal detatchment were diagnosed in the unilateral injections group. There were no cases of retinal detachment in the bilateral group.

\section{Discussion}

Bilateral same-day injections are common in many countries and are our choice in patients who need injections in both eyes. They are time-saving for the patients, their family, and the physician. The convenience is unquestionable, but safety concerns have been raised. In current literature, many articles have been written in this topic, but no conclusion has been reached.

A large study with 1,534 same-day bilateral intravitreal anti-VEGF (in 367 patients) explored the incidence of complications after this procedure. Three complications were acknowledged: two unilateral culture-proven endophthalmitis $(0.065 \%)$ and one unilateral acute intraocular inflammation $(0.033 \%) .{ }^{1}$ These rates seem comparable to those found for unilateral injections $(0.078 \%-0.022 \%))^{11,12}$ But this kind of comparison from different studies, with different conditions, can be misleading. In this study, we minimize this bias, evaluating injections made in the same hospital, by the same two surgeons, with two anti-VEGFs. No culture-proven endophthalmitis was diagnosed in the bilateral injections group, and the rate of acute intraocular inflammation was lower in the same-day bilateral injection group when compared with the unilateral group $(0.062 \%$ vs $0.152 \%)$. The patient diagnosed with acute intraocular inflammation in the bilateral injections group had no signs of inflammation in the fellow eye.

Interestingly, aflibercept had a higher rate of acute intraocular inflammation than ranibizumab $(0.688 \%$ vs $0.178 \%)$.

Table 3 Distribution of endophthalmitis per year and anti-angiogenic

\begin{tabular}{|c|c|c|c|c|c|}
\hline \multirow[t]{2}{*}{ Year } & \multicolumn{2}{|c|}{ Acute intraocular inflammation } & \multicolumn{2}{|c|}{ Culture-proven endophthalmitis } & \multirow[t]{2}{*}{ Total } \\
\hline & Ranibizumab & Aflibercept & Ranibizumab & Aflibercept & \\
\hline 2011 & 1 & - & - & - & I (0.135\%) \\
\hline 2012 & - & - & - & - & $0(0 \%)$ \\
\hline 2013 & I & 2 & - & - & $3(0.125 \%)$ \\
\hline 2014 & 9 & 2 & - & - & I I (0.595\%) \\
\hline 2015 & 2 & 2 & I & - & $5(0.876 \%)$ \\
\hline 2016 & - & - & - & - & $0(0 \%)$ \\
\hline \multirow[t]{2}{*}{ Total } & $13(0.178 \%)$ & $6(0.688 \%)$ & I (0.0I4\%) & $0(0 \%)$ & $20(0.245 \%)$ \\
\hline & $19(0.233 \%)$ & & I (0.0I2\%) & & \\
\hline
\end{tabular}


It has a substantial difference that should be taken into account in future studies.

We had a higher culture-proven endophthalmitis rate than we expected $(0.110 \%)$. The year 2014 contributed significantly with seven of the nine cases, but we do not find any reasons for this discrepancy. Also, aflibercept injections had an unexpected higher rate.

The levels of serum VEGF after bilateral injections are also a concern, but Wang et $\mathrm{a}^{17}$ found no significant difference in pre- and postinjection serum levels of VEGF between unilateral and bilateral intravitreal anti-VEGF. This way, similar systemic effects of unilateral and bilateral injections are expected. But, since serum half-life of bevacizumab is known to be less than 1 week, ${ }^{17,18}$ and the measurements were made 1 month postinjection, an earlier postoperative observation could have bigger differences.

\section{Conclusion}

In our opinion, bilateral same-day injections are very well tolerated by patients, time-saving, and economically more favorable. In our study, the rate of endophthalmitis was lower in the bilateral injection group.

Despite being a retrospective study, these results add some important information for our daily practice and help us to make a more informed choice.

\section{Disclosure}

The authors do not have any financial interest or competing interests in the methods and devices mentioned in this presentation. The authors report no conflicts of interest in this work.

\section{References}

1. Lima LH, Zweifel SA, Engelbert M, et al. Evaluation of safety for bilateral same-day intravitreal injections of antivascular endothelial growth factor therapy. Retina. 2009;29(9):1213-1217.

2. Rosenfeld PJ, Brown DM, Heier JS, et al. Ranibizumab for neovascular age-related macular degeneration. $N$ Engl J Med. 2006;355(14): $1419-1431$.
3. Wolf S, Balciuniene VJ, Laganovska G, et al. RADIANCE: a randomized controlled study of ranibizumab in patients with choroidal neovascularization secondary to pathologic myopia. Ophthalmology. 2014;121(3):682-692.e2.

4. Bakri SJ, Risco M, Edwards AO, Pulido JS. Bilateral simultaneous intravitreal injections in the office setting. Am J Ophthalmol. 2009; 148(1):66-69.e1.

5. Green-Simms AE, Ekdawi NS, Bakri SJ. Survey of intravitreal injection techniques among retinal specialists in the United States. Am J Ophthalmol. 2011;151(2):329-332.

6. Abu-Yaghi NE, Shokry AN, Abu-Sbeit RH. Bilateral same-session intravitreal injections of anti-vascular endothelial growth factors. Int $J$ Ophthalmol. 2014;7(6):1017-1021.

7. Chao DL, Gregori NZ, Khandji J, Goldhardt R. Safety of bilateral intravitreal injections delivered in a teaching institution. Expert Opin Drug Deliv. 2014;11(7):991-993.

8. Davis RP, Schefler AC, Murray TG. Concomitant bilateral intravitreal anti-VEGF injections for the treatment of exudative age-related macular degeneration. Clin Ophthalmol. 2010;4:703-707.

9. Mahajan VB, Elkins KA, Russell SR, et al. Bilateral intravitreal injection of antivascular endothelial growth factor therapy. Retina. 2011; 31(1):31-35.

10. Woo SJ, Han JM, Ahn J, et al. Bilateral same-day intravitreal injections using a single vial and molecular bacterial screening for safety surveillance. Retina. 2012;32(4):667-671.

11. Diago T, McCannel CA, Bakri SJ, Pulido JS, Edwards AO, Pach JM. Infectious endophthalmitis after intravitreal injection of antiangiogenic agents. Retina. 2009;29(5):601-605.

12. Fintak DR, Shah GK, Blinder KJ, et al. Incidence of endophthalmitis related to intravitreal injection of bevacizumab and ranibizumab. Retina. 2008;28(10):1395-1399.

13. McCannel CA. Meta-analysis of endophthalmitis after intravitreal injection of anti-vascular endothelial growth factor agents: causative organisms and possible prevention strategies. Retina. 2011;31(4):654-661.

14. Martin DF, Maguire MG, Ying GS, Grunwald JE, Fine SL, Jaffe GJ. Ranibizumab and bevacizumab for neovascular age-related macular degeneration. N Engl J Med. 2011;364(20):1897-1908.

15. Merani R, Hunyor AP. Endophthalmitis following intravitreal antivascular endothelial growth factor (VEGF) injection: a comprehensive review. Int J Retina Vitreous. 2015;1:9.

16. Fenoll MA. [ARCSTERILE: A COST-EFFECTIVE LUXURY]. Rev Enferm. 2015;38(5):8-12. Spanish.

17. Wang D, Choi KS, Lee SJ. Serum concentration of vascular endothelial growth factor after bilateral intravitreal injection of bevacizumab. Korean J Ophthalmol. 2014;28(1):32-38.

18. Davidovic SP, Nikolic SV, Curic NJ, et al. Changes of serum VEGF concentration after intravitreal injection of Avastin in treatment of diabetic retinopathy. Eur J Ophthalmol. 2012;22(5):792-798.
Clinical Ophthalmology

\section{Publish your work in this journal}

Clinical Ophthalmology is an international, peer-reviewed journal covering all subspecialties within ophthalmology. Key topics include: Optometry; Visual science; Pharmacology and drug therapy in eye diseases; Basic Sciences; Primary and Secondary eye care; Patient Safety and Quality of Care Improvements. This journal is indexed on Submit your manuscript here: http://www.dovepress.com/clinical-ophthalmology-journal

\section{Dovepress}

PubMed Central and CAS, and is the official journal of The Society of Clinical Ophthalmology (SCO). The manuscript management system is completely online and includes a very quick and fair peer-review system, which is all easy to use. Visit http://www.dovepress.com/ testimonials.php to read real quotes from published authors. 